\title{
Jong Sub Park, M.D., 1932 to 2016
}

\author{
Min Sung Tak \\ Department of Plastic and Reconstructive Surgery, Soonchunhyang University Hospital, Soonchunhyang \\ University College of Medicine, Seoul, Korea
}

Professor Jong Sub Park (Figure) was a truly passionate man, motivating and influencing others. Unfortunately, in 2016, Professor Park passed away, and we lost one of our greatest plastic surgeons.

Professor Park was born on September 24, 1932. He studied at Chonnam National University School of Medicine from 1953 to 1959. Shortly after graduation, he completed his residency in the Department of General Surgery at Yonsei University Severance Hospital. Afterwards, Professor Park continued on with a fellowship in the Department of Plastic Surgery for two years at the same hospital.

In 1975, Professor Park passed the first plastic surgery specialty exam and became a specialist in plastic surgery. In 1978, he became the first head of the Department of Plastic and Reconstructive Surgery in Soonchunhyang University Hospital. He then served as the 14th Chair of the Korean Society of Plastic and Reconstructive Surgeons in 1991 and as the Director of Soonchunhyang University Cheonan Hospital in 1995.

The legacy of Professor Jong Sub Park runs parallel with the history of plastic surgery in Korea. In the summer of 1973, the fundamental construction work for Soonchunhyang, one of the largest hospitals in Korea at that time, was in progress in Hannam-Dong in Seoul. Professor Park visited the Seoul Soonchunhyang Hospital construction site, and his relationship with Soonchunhyang was established soon after.

Generally, Professor Park had a relaxed personality, but he was notorious for being very strict when it came to education. Residents who received training from Professor Park confess they could not even look Professor Park straight in the eye. Professor Park would pour questions out to the residents in the operating room, and if he did not hear a satisfactory answer, he would sigh and the entire room would tense up.

Despite the intense tension he stirred up in students, he was known to be a warm, kindhearted physician when it came to patient care. There is a famous story about Professor Park. There was a patient who created a scene by complaining and yelling during clinic hours. Professor Park invited the patient to his office and talked with the patient. To everyone's surprise, the patient became very polite and left without causing any more problems. There were multiple times when similar events took place with various patients. Even to this day, no one knows what happened or what was discussed in Professor Park's office with those patients. 
However, Professor Park was extremely strict and had no exceptions when it came to residents' patient care. When patients complained about the care provided by a resident, Professor Park scolded the residents. If residents became upset because they believed they had not done anything particularly wrong, Professor Park scolded them further and advised them that physicians should always try to treat patients with kindness and sincerity.

Professor Park was an amazing teacher, surgeon, father, and mentor with a warm and gracious heart. Sung Jin Park, son of Professor Park, is also a plastic surgeon. He said, "My father had a week for summer vacation, but he always went back to his work at the hospital 3-4 days after [his vacation began]. Although he was sometimes considered to be a workaholic and living a dull life, he enjoyed his life. Father said, 'Patients are not there for me. I am there for them. So I would rather help them than just stay at home.' I say this not just because he is my father: I think he was a truly respectworthy doctor."

Since Professor Park left this world, several things have changed. The world of medicine has seen changes, and patient perspectives of physicians have changed as well. However, the lessons given by Professor Park have been passed down and continue to be the fundamentals of patient care for physicians.

Professor Park influenced not only his family but also the following generations, doctors, and plastic surgery in Korea. The life of Professor Park as a doctor, father, and an individual is truly honorable. May he rest in peace.

Correspondence: Min Sung Tak

Department of Plastic and Reconstructive Surgery, Soonchunhyang University Hospital, Soonchunhyang University College of Medicine, 59 Daesagwan-ro, Yongsan-gu, Seoul 04401, Korea

Tel: +82-2-709-9283, Fax: +82-2-796-3543, E-mail: tarkms@naver.com

No potential conflict of interest relevant to this article was reported.

Received: 6 Oct 2016• Revised: 4 Nov 2016 • 6 Nov 2016

pISSN: 2234-6163・ elSSN: 2234-6171

https://doi.org/10.5999/aps.2016.43.6.625• Arch Plast Surg 2016;43:625-626 